\title{
Relevance of Public Administrations: Visualization of Shifting Power Relations in Blockchain-Based Public Service Delivery
}

\author{
Maik Brinkmann \\ University of Potsdam \\ job@,mbrinkmann.com
}

\begin{abstract}
Power relations within the area of blockchain governance are complex by definition and a comprehensive analysis that links technological and institutional elements is missing to date. The research that is presented with this article focuses on the visualization of the shifting power relations with the introduction of blockchain. For this purpose, the analysis leverages an adjusted version of the multistakeholder influence mapping tool. The analysis considers the various stakeholders within the multilayered blockchain technology stack and compares three fundamental blockchain scenarios, including public and private blockchain settings.

The findings show that public administrations face indeed less power with the introduction of blockchain, while new stakeholders come into play who wield influence rather uncontrolled. Nonetheless, public administrations are not powerless overall and remain influential stakeholders. This paper concludes that blockchain governance is not as democratic as blockchain enthusiasts tend to argue and derives corresponding opportunities for further research.
\end{abstract}

\section{Introduction}

Public administrations and political representatives regard joint efforts between public and non-public stakeholders to produce public services as increasingly important. This is a reaction to pressing topics resting inside and outside public administrations, such as scarce public funds, limited internal resources, eroding trust of society and challenges of globalization. A prime example for the current need of collaboration between public and nonpublic stakeholders is the ongoing global health crisis due to COVID-19. Observed governmental responses (e.g. [1]) actively ask for a close collaboration between public health authorities and citizens with combined resources in order to co-produce public health services. In general, this governance-focused paradigm is often referred to as New Public
Governance [2]. A successful implementation of this paradigm also requires the ability to cope and align with multiple involved stakeholders.

There are already various solutions of information technology (IT) available to support collaborative modes of working. However, the technology of blockchain takes the discussion of scholars and practitioners to another level because this technology is attributed to act as an institutional technology [3]. Scholars of IT often claim it could fundamentally redefine stakeholder interactions by offering secure peer-to-peer working styles and thereby even improve democracy [4]. Advocates of blockchain also question the role of public administration. At the same time, the discussion around the institutional consequences of blockchain is rather unstructured. It is the technological complexity and the high number of relevant stakeholders on governance level that makes it difficult to understand the technology itself and corresponding power relations. For this reason, further research is demanded that links technological and institutional perspectives [5].

The research presented with this article aims to structure and visualize the shifting power relations in the area of blockchain governance by applying comprehensive stakeholder analysis techniques, such as multi-level stakeholder influence mapping tool [6]. Furthermore, the research seeks to evaluate possibilities and limitations of public administrations to influence the development of blockchain-based public services.

This article summarizes the efforts and results of this research. First, the theoretical foundations of this research are laid out with an overview of interorganizational public service delivery and the blockchain technology. Second, the design of this research is introduced in greater detail by describing the applied step-by-step approach. Third, major findings are then examined and discussed. And finally, conclusions are drawn with respect to the aim of this research before limitations to the results and opportunities for further research are discussed. 


\section{Background}

This chapter elaborates on the theoretical foundations of this article. First, the shift from intraorganizational towards interorganizational governance is presented and amplified with a discussion on the role of power and e-governance. Second, the foundations of the blockchain technology are introduced. These also include elaborations on the matters of blockchain governance and the technology's multiple stack layers.

\subsection{Public service delivery - towards interorganizational governance}

Public administrations offer public goods and services to their various stakeholders and expect them to follow their rules and to pay tax. The public administrations do so as they largely rely on laws and potential penalties these may include [7]. They provide those goods and services with limited capacities. Especially time, funds and knowledge about the interdependences of service provisioning are scarce $[8,9]$. Latter limitation should not surprise when multiple stakeholders are involved or even national boundaries are crossed [10] in consequence of e.g. technologies that know no borders or supply chains that easily span across nations [11, 12]. Additionally, private actors increasingly engage as public service providers [9]. Thus, the number of elements of a public service increases which makes it harder to predict and control the service outcomes, i.e. the complexity increases $[13,14]$.

As one of the most recent and popular public sector reforms, New Public Management fails to offer adequate responses to these constraints due to its intraorganizational focus on efficiency [15]. Accordingly, new approaches are required that consider the shifting roles [16] and tackle the growing interorganizational governance efforts within the public service delivery system [10]. Collaborative forms of governance have thereby gained significant importance in public sector reforms [17] because traditional patterns of policy making, e.g. top-down decision-making or confrontation, appear to be hardly suitable for recent challenges [18]. These forms seek to resolve conflicts and facilitate cooperation among public and non-public stakeholders [19] in order to improve efficiency and quality of public services. This governance-focused paradigm is also referred to as New Public Governance. With New Public Governance, public and non-public stakeholders combine their resources to provide public services in co-production [2].
Indeed, this would be a promising development. At the same time, this development presents "a challenge to the role of government" [15] which requires careful examination. When activities are not provided by public administration any longer, but instead by non-public stakeholders, this raises concerns in terms of e.g. accountability, legitimacy [15] or governability of the societal system [11]. There are many factors that could influence this complex governance system and which can only be partly controlled by the governing system [11]. Stakeholders are likely to bring in diverging sets of e.g. goals, capacities, interests and dependencies [10]. This may give reason for "conflicts and power issues" [20] leading to challenging coordination and balancing efforts [21] to finally jointly provide public services. Companies could either struggle in case they have to follow divergent laws of multiple jurisdictions or assume a superior role if they can rely on a large-scale organization and corresponding resources, while latter scenario is rather common practice and not theoretical thought experiment [21]. In summary, effective strategies for coordination and cooperation in governance networks are essential to prevent unbalanced actions, the abuse of power by stakeholders or an inadequate provision of public services [22].

Consequently, power and influence are two important factors in governance networks. The two concepts are closely linked with each other but still can be clearly distinguished. Both concepts strive for the achievement of one's actor interest. In contrast to the power, influence can achieve the interests without any forces or sanctions [23, 24]. Using power always means to rely on a basis of power, e.g. knowledge, resources [6] or authority. Interestingly, where power and influence lie and how they are "conceived in studies of governance and institutions is often not discussed." [6] This issue needs to be tackled when stakeholders apparently play an increasing role in governance networks. It can help to better understand stakeholder relationships within governance networks and, subsequently, support the design of proper governance models [6].

The analysis of stakeholders in governance networks that follow the concept of New Public Governance should also consider the use of IT. Electronic government is widely integrated in today's governmental processes of policymaking and policy implementation [25]. Thus, transforming a public administration would go along with a complementary transformation of IT. The benefits of IT for governance purposes, or e-governance, is already being discussed today. There are claims e-governance could result in intrinsically changed relationships in 
society and "help to achieve democratic means and even transform people's social and political consciousness." [26] Furthermore, e-governance should e.g. increase the efficiency, the accessibility of data and also enable a power shift from governments to individuals [4].

Interestingly, the idea of conflicting interests and powers relations within collaborative governance networks to provide public services needs to be expanded onto the technology level [4]. The more stakeholders are involved with their own IT capacities, the higher the overall dependence on these IT assets [21]. And due to high complexities in IT provisioning (e.g. cloud-based public services operated by third parties in data centers across the world), it is hard to tell where power lies in the end [4]. Elsner [21] already claimed years ago that an analysis should focus on the roles of power. This claim still holds true because the rather new technology of blockchain raises high hopes to fundamentally change the interactions among stakeholders. Does the introduction of blockchain represent a shift in powers for the provision of public services? In which direction - vertically and horizontally?

\subsection{Blockchain - the institutional technology of governance}

Blockchain is a distributed ledger technology which allows to securely transfer digital assets of any kind from one user to another in a peer-to-peer fashion. Thus, it can be applied to a variety of fields of application [27]. The most prominent use of blockchain can be observed within the field of cryptocurrencies, e.g. Bitcoin or Ether as being two well-known cryptocurrencies. Essentially, blockchain is a network of nodes that stores continuously updated and synchronized data based on predefined rules every node agreed to. Self-executable programs, so-called smart contracts, further improve the efficiency of transactions [28] and reduce the need of human intervention.

Although blockchain is described by an alternating number of characteristics [29], there are four essential characteristics which in combination build the strength of this technology [30]: immutable data as a result of cryptography and the unique design of blocks, decentralized and bidirectional exchange between users without an intermediary, consensus among nodes that the stored data is accurate and a transparent history of all transactions [30].

Furthermore, blockchain is not a monolithic system. It rather is an ecosystem of multiple, interconnected layers [28]. There are different approaches to organize the layers depending on whether it should only entail technical layers or also institutional layers [31]. With regard to this article's aim, it was decided to rely on the technical layers. The sum of all technical layers will be called blockchain technology stack $[32,33]$ in the following. Table 1 introduces the layers of the blockchain technology stack and presents a brief description per layer.

\begin{tabular}{ll} 
Table 1. Layers of the blockchain \\
technology stack \\
\hline $\begin{array}{l}\text { Technology } \\
\text { stack layer }\end{array}$ & Brief description \\
\hline Application & This layer sits on top of the \\
& blockchain layer and includes so- \\
& called decentralized applications \\
& (DApps) and supporting \\
& application frameworks. DApps \\
& are stored on the blockchain and \\
& executed by the nodes [28]. \\
& Stakeholders at this level can be \\
& e.g. software developers or end \\
& users. \\
This layer essentially includes the \\
consensus mechanism of the \\
blockchain network [28, 34], e.g. \\
proof-of-work or proof-of- \\
authority. It contains the rules \\
how transactions are validated \\
and subsequently stored by the \\
nodes [31]. Also, fundamental \\
characteristics of a blockchain \\
network, such as permissionless \\
access, can be assigned to this \\
layer. Stakeholders at this level \\
can be e.g. node operators or core \\
software developers.
\end{tabular}

The essential blockchain characteristics of this multi-layered network have been leading to an increasing interest in blockchain among scientists and practitioners [36]. Because blockchain represents a fundamental change of user interaction and its presumed impact on common roles, with intermediaries being potentially eliminated [37], this technology is perceived as an institutional technology of governance [34]. Intermediaries, it is argued, may 
often leverage information asymmetry out of selfinterest or in "inefficient, or corrupt ways." [38] While blockchain is thus presented as the solution to these issues, others argue (e.g. [39]) the introduction of blockchain may give rise to new challenges to overcome self-interest of stakeholders.

In general, potentials to use and participate in a blockchain network depend on configuration where two fundamentals can be distinguished. A public and permissionless blockchain solution (e.g. Bitcoin or Ethereum) is open to any individual or organization that wants to use, operate or further develop the network for their individual reasons. A public blockchain can be accessed globally, not bound by borders, which makes it hard for single public entities to enforce the law of their own jurisdiction. Adequate governance of this network appears to be challenging due to its open nature [40]. In contrast to public blockchains, private blockchains seem easier to handle in terms of governance. They rely on central authorities, normally the owners of the networks organized in a consortium, who have the say when it comes to fundamental decisions and they also decide on user access and privileges [5, 28]. But it is precisely the centralized setup which leaves room for criticism since it could be interpreted as a contradiction to blockchain's idea of decentralization [28]. However, owners rely on the private setup in hope for efficiency gains [28] and increased governability [41].

There is a larger consensus among scientists that the choice to go for a public or private blockchain influences the governability of a blockchain network. However, this is a rather vague conclusion of the institutional consequences and the roles that are likely to change. Proper scientific analyses are rare to date. This is not surprising because most scientists still focus on cryptocurrencies and technical issues of blockchain [36]. Therefore, it is argued in favor of further assessments $[40,42]$. This seems necessary to better understand the effects on governance associated with the selection of either private or public blockchains and to pinpoint "risks and drawbacks" [40], wherever they occur. This could provide handson orientation to scientists and practitioners alike and contribute to the discussion on blockchain governance models.

Blockchain governance essentially refers to two principles: governance by blockchain and governance of blockchain [35]. When blockchain is leveraged to govern non-technical, functional processes (e.g. collaborative public services between a public administration and its citizens) or organizations, this governance is achieved by the use of blockchain. Blockchain itself requires its own governance structures and processes because it is in a constant process of development, operation and maintenance [5]. This is referred to as governance of blockchain. Governance decisions affecting the blockchain network can have an impact on the qualities of governance by blockchain.

On-chain or off-chain procedures can be applied to implement governance by or of blockchain. Onchain governance refers to technical rules directly embedded into the code allowing a more efficient and strict way of implementation [28, 35]. For instance, rules embedded on the blockchain layer will be mandatory for the upper application layer and its DApps and frameworks. Processes and other forces of off-chain governance, however, affect a blockchain network and its stakeholders from the outside [35]. These forces, e.g. national laws or informal rules of communities, "operate at the social and institutional level, rather than at the technical level." [35] Consequently, the human factor comes into play which makes off-chain governance more complex and less predictable than on-chain governance.

The social and institutional factor at governance level presents a challenge to blockchain networks. The initial intention of blockchain enthusiasts was to take away power from centralized stakeholders and distribute the power to many other individuals [28], "enabling a more even distribution of power and wealth... [and leading] to increased participation and public engagement." [35] This belief is to be challenged with respect to the stakeholders at each blockchain stack layer. Governance of blockchain partly requires new roles, e.g. core software developers of public blockchains, that coexist with established roles. So, there might be a shift of power from today's centralized stakeholders. But this brings up two questions: How much power is shifted really? Are there new powerful centralized stakeholders instead of an even distribution of power?

Some scientists already estimate that blockchain networks could give rise to oligarchies at technology level [35, 42, 43] who could ultimately impact nonblockchain related, functional or political governance decisions. Power would be "still divided unequally." [44] It is the aim of this article to examine these claims by a clear presentation of possible new power relations in blockchain networks.

\section{Methodology}

This chapter introduces the methodology, including a step-by-step process description. This methodology is built on multiple complementary tools of stakeholder analysis. It is this mix of tools that allows to achieve this article's aim of structuring and 
visualizing shifting power relations among stakeholders.

It was concluded in the previous chapter that stakeholder analysis is often neglected within governance sciences. Not surprisingly, the number of tools for practitioners and researchers alike to understand power relations and define appropriate measures [6] to shape governance models is limited. Within the area of stakeholder analysis, however, the decisional method provides a promising approach to gain this understanding by considering qualitative data and investigating "power according to [stakeholders'] participation in decision-making." [45] This method contains tools like the power versus interest grid, bases of power and direction of interest diagram and the stakeholder influence mapping [45]. It is the adoption of latter by Sova et al. [6], in particular, that offers a valuable methodological foundation for this article's research - the Multi-level Stakeholder Influence Mapping (MSIM).

Similar to the stakeholder influence mapping (SIM), MSIM seeks to analyze the relationship of stakeholders or stakeholder groups towards a decisionmaking scenario or policy focus "within complex system regimes." [6] It does not primarily aim at investigating the relationship among stakeholders. These relationships are only relevant by extension [6]. The influence of one stakeholder on the policy focus is of particular interest [46]. The enhancement and great advantage of MSIM over SIM lies in its ability to create an comprehensive view on one policy focus spanning across multiple stakeholder levels [6].

Depending on the level of aggregation, results of the stakeholder analysis merge into one or more visual maps, each containing individual stakeholder characteristics, including the relevant stakeholders and their group size, "the degree of influence that they hold over the [scenario], and their relationships with each other." [46] The closeness of stakeholders to one another displays the degree of potential conflict or cooperation [6].

To gather those stakeholder characteristics, the commonly used step-by-step approach needs adjustments to meet the article's aim in response to the low number of available blockchain implementations in the public sector. The original interview-based approach which would allow to identify stakeholders, their group size and influence is, thus, replaced by a comprehensive desk research in combination with the additional use of tools of stakeholder analysis. The following adjusted, stepwise MSIM approach was applied for this research:

Step 1: Define policy focus. The policy focus reflects the overall issue in scope [46] of this research. The influence of stakeholders is measured by the stakeholder's influence on the policy. Because this research seeks to compare blockchain and nonblockchain scenarios, the policy focus needs to be framed more general and not exclusively to meet blockchain scenarios. Consequently, the policy focus for this research is phrased "Establishing and making adjustments to domestic public service".

Step 2: Define scenarios. Scenarios are usually defined to understand the development of stakeholder influence on a policy focus over time [6]. In this research, those scenarios are derived from the three fundamental options to use or not to use blockchain: Private blockchain, public blockchain and conventional use of IT, i.e. no blockchain is used.

To increase the usability of this research's results, existing blockchain implementations were considered. With respect to the private blockchain, the Swedish Mapping, Cadastral and Land Registration Authority implemented a solution to transfer land titles. The public blockchain scenario is represented by the Ministry for Education and Employment of Malta that implemented a solution to issue and authenticate educational credentials. The conventional scenario is based on characteristics of the IT of both the Swedish and Maltese public administrations (e.g. use of cloud services by third parties) gathered by literature research to support a before and after comparison as realistic as possible.

Step 3: Identify appropriate stakeholder levels. As shown with section 2.2, the blockchain network is not a monolithic system. It rather consists of three essential stack layers, i.e. application layer, blockchain layer and internet layer. These stack layers can be applied to the private and public blockchain scenarios. Correspondingly, appropriate layers for the conventional scenario are application layer, public administration infrastructure layer and internet layer. Latter layer refers to the same layer as within the blockchain scenarios. In contrast to blockchain's decentralized application layer, the conventional application layer is rather focused on centralized applications. Additionally, the public administration infrastructure layer is founded on the widely exercised Do-It-Yourself approach of public administrations to run their own IT development and operations units supported by third parties.

Step 4: Identify stakeholders. An extensive literature review on (non-)blockchain stakeholders was conducted. The literature revealed a wide range of stakeholders for blockchain in general, but some of them appeared not be relevant for the respective scenarios. Only stakeholders relevant for at least one scenario were considered going forward and mapped to each scenario and layer, if applicable. Results were noted in a stakeholder list. 
Step 5: Estimate group size. For each relevant stakeholder, the group size was estimated and classified in categories of "smallest", "small", "big" and "biggest". The information per stakeholder was added to the stakeholder list.

Step 6: Determine stakeholder influence and relationships. This is a key step of this methodology and a divergence from the conventional MSIM methodology. Instead of relying on interviews to gather opinions from individuals, there was another extensive literature review conducted on the relevant stakeholders. The aim was to explore and structure the broader scientific opinion on the interests and power base of each stakeholder at each stack layer in each scenario by leveraging the "bases of power and directions of interest" tool [47]. There are especially the bases of power, e.g. in the shape of coercion, legal force, knowledge or resources [6, 48, 49], that decide whether a stakeholder is rather likely to safeguard its interest compared to other involved stakeholders. This is crucial to substantiate the decision on a stakeholder's influence [47]. Furthermore, possibly identified similarities or differences between stakeholders can be used to estimate the closeness among them. The stakeholder information on power and interests was then again added to the stakeholder list.

Step 7: Assign stakeholder ranking. This step involves the assignment of a relative ranking to a stakeholder within each scenario and stack layer. This assignment is based on the evaluation of the different bases of power and directions of interest of each stakeholder. A stakeholder's influence on the policy focus is ranked higher, when this stakeholder e.g. has relevant legal authority to enforce its interests. In contrast, another stakeholder may be in a contractual relationship which rather coerces this stakeholder to follow the will of others. "The [stakeholder] placed lowest received a ranking score of 1 , the second lowest a score of 2" [6] and so on. Stakeholders can also receive the same ranking score. This variable is referred to as relative ranking (R). Once the assignment is completed, influence maps per stack layer can be created.

Step 8: Calculate influence score. The influence score (InfS) is the most relevant stakeholder variable for this research. The influence score is an aggregated variable answering the question what the overall influence of one particular stakeholder is on a scenario - regardless of the frequency this stakeholder was identified as relevant in a scenario. Because the number of stakeholders can vary across stack layers in a scenario, it is important to transfer the relative rankings of a stakeholder into an adjusted ranking score ( $\mathrm{Ra}$ ) on scenario level. This is the base to calculate the influence score of each stakeholder. At the end of the calculation, the influence map per scenario level can be created.

Step 9: Compare scenarios. In order to understand the changing power relations across scenarios, an adequate method to compare the stakeholder influence across scenarios was designed. Instead of adding another number to this qualitative research, it was decided to use a qualitative scale ranging from "High influence" at the top to "Low influence" at the bottom. This scale was applied to the calculated influence score derived within step 8 .

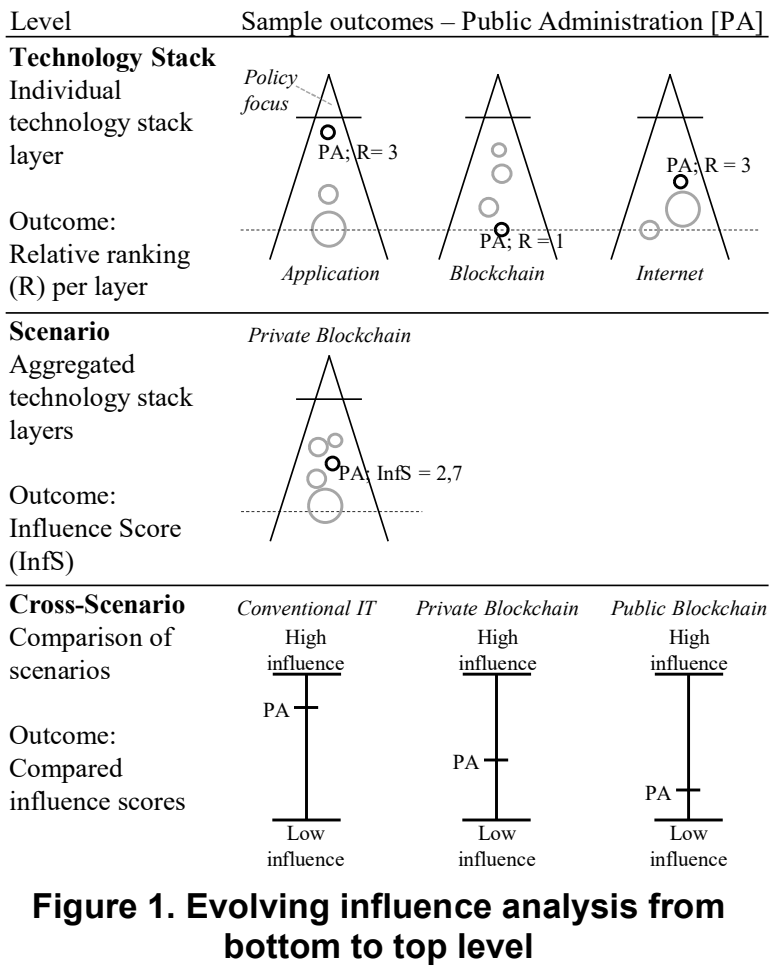

In summary, this approach not only provides insights into each stack layer, but also allows an aggregation from the bottom to the top. Figure 1 illustrates the expected result types for each level and how those result types are linked between the levels.

\section{Results and discussion}

This chapter presents the major results obtained by applying the methodology presented in the third chapter and puts them into perspective. More details on all relevant stakeholders and scenarios, including influence maps, influence scores and rankings, are provided as supplemental files alongside this article.

The results of this research show that there are eleven relevant stakeholders to consider across all 
three scenarios. The composition reflects the different roles within a scenario and stack layer, and diverging characteristics of a stakeholder. For example, it was decided to split "end user" into two stakeholder groups consisting of "end user (citizens)" and "end user (company)" due to significant differences in group size and bases of power, which could impact the analysis.

The data of this analysis shows that the number of relevant stakeholders varies across all scenarios and stack layers. Most stakeholders could be identified within the public blockchain scenario whereas the conventional IT scenarios contains the least number of stakeholders. Also, stakeholders are not constantly relevant within and across scenarios, although the frequency of appearance does not necessarily correlate with the stakeholder's overall influence. Interestingly, even the group size of one stakeholder can fluctuate depending on the scenario. Thus, a particular group size should not be taken for granted when designing governance models.

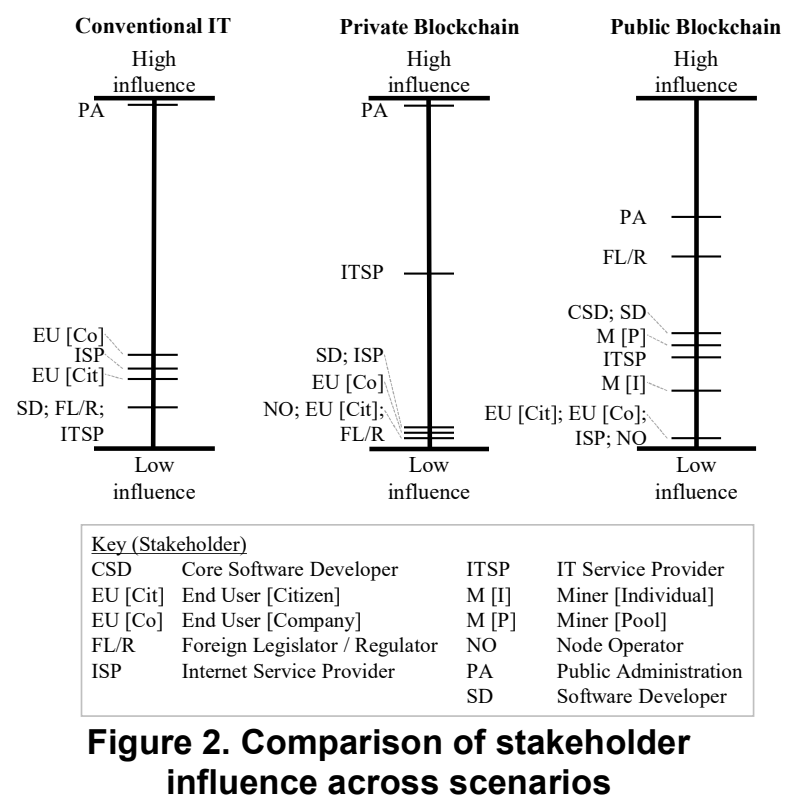

For public administrations, opportunities for decision-making constantly decrease from the conventional IT, through the private to the public blockchain scenario (see Figure 2). This is understandable because they gradually lose ownership of IT and other stakeholders can make decisions on issues that were formerly solely decided by public administrations. This is especially true with respect to the public blockchain of Malta. In this public blockchain scenario, the Maltese public administration can hardly influence what decisions should be made and how this should happen. Large stakeholder groups, mainly positioned outside the Maltese jurisdiction, make it difficult for the Maltese public administration to ensure its demands are considered. On the blockchain stack layer, in particular, other stakeholders, i.e. core software developer, mining pools and foreign regulators, seem to set the agenda (see Figure 3 ). This is a major change compared to the conventional IT scenario.

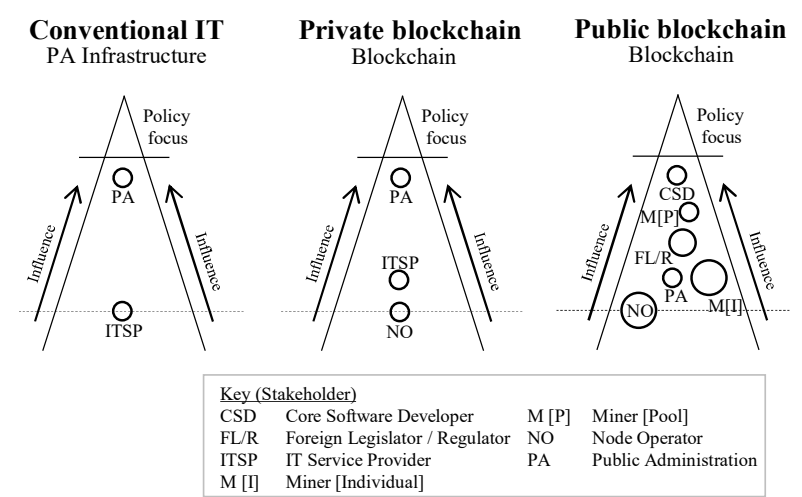

Figure 3. Comparison of the middle layers of the technology stack

Overall, public administrations seem to have less power but they are not powerless. Because the Swedish and Maltese public administrations could act on all stack layers to a certain extent, makes them influential players nonetheless. In contrast, end users (citizens and companies) only play a minor role, if any, when it comes to influencing blockchain-related events or taking part in decision-making processes. Apparently, civic end users cannot leverage their sheer group size to push their manifold interests.

Finally, IT service providers gain influence from their valuable resources and capacities they bring in. Public administrations struggle and hesitate to recruit such specialized and rare professionals. IT service provider fill this gap and act as co-producers of public services [50].

\section{Conclusion}

The research presented with this article aimed to gain a deeper understanding of the shifting power relations within the area of blockchain governance to deliver public services. For this purpose, the power relations among relevant stakeholders were visualized and the possibilities and limitations of public administrations, in particular, to influence the development of blockchain-based public services evaluated.

The results allow a tangible picture of the shifting power relations, as intended. It was shown that public 
administrations are not powerless in any scenario. Compared to conventional IT solutions, however, their possibilities decrease especially with the use of public blockchains. Furthermore, limitations in decision making on all layers of the blockchain technology stack became apparent. Public administrations would need to enter into transnational partnerships to effectively increase the influence on public blockchains.

The results indicate that public administrations should rather leverage private blockchain solutions if they are interested in keeping control. At the same time, private blockchains could mean higher initial costs because of additional efforts to set up consortium partnerships and the need for dedicated IT infrastructure. From a research perspective, a rising number of private blockchains increases the importance of interoperability to interlink private blockchains and, thereby, strengthen the usability of blockchain-based solutions.

The decision to either use private or public blockchains is not only a technical one. It may also impact the development of public services based on collaborative governance. Public blockchains, especially Bitcoin, are not tools to support truly democratic governance procedures. As long as citizens, who represent the largest stakeholder group by far, have little or no opportunity to participate in this development, the development of blockchain networks remains a task of a few, privileged stakeholders. For the time being, public administrations could make a difference by choosing private blockchains and designing more inclusive governance models. Consequently, further research should elaborate on the ways to include citizens or adequate representatives in the process of blockchain governance.

Although this research was carefully conducted, there are two limitations to the findings. First of all, the data basis for the presented results is only partly empirical. There are very limited implementations within the public sector available which consequently narrows the experience of relevant stakeholders with matters of blockchain governance. Second, the calculation of the stakeholder influence scores is the result of qualitative methods of stakeholder analysis. As with any other qualitative method, this allows deviations with respect to the accuracy. To tackle both limitations, it is suggested to conduct interviews with relevant stakeholders, once available in sufficient numbers, to analyze the perceptions of those directly affected. This would allow the results of this research to be reviewed.

\section{References}

[1] German Federal Government. 2020. Corona-WarnApp. Help us in the fight against corona. https:/www.bundesregierung.de/bregde/themen/corona-warn-app/corona-warn-appenglisch.

[2] Osborne, S. P. 2010. The (New) Public Governance. a suitable case for treatment? In The new public governance. Emerging perspectives on the theory and practice of public governance, S. P. Osborne, Ed. Routledge, London, New York, 1-16.

[3] Campbell-Verduyn, M., Ed. 2018. Bitcoin and beyond. Cryptocurrencies, blockchains, and global governance. RIPE series in global political economy. Routledge, London, New York.

[4] Fisher, E. 2012. E-Governance and E-Democracy. Questioning Technology-Centered Categories. In The Oxford Handbook of Governance, D. Levi-Faur, Ed. Oxford Univ. Press, Oxford, 569-583.

[5] Ølnes, S., Ubacht, J., and Janssen, M. 2017. Blockchain in government. Benefits and implications of distributed ledger technology for information sharing. Government Information Quarterly 34, 3, 355-364.

[6] Sova, C. A., Helfgott, A., S. Chaudhury, A., Matthews, D., F. Thornton, T., and J. Vermeulen, S. 2015. Multi-level Stakeholder Influence Mapping. Visualizing Power Relations Across Actor Levels in Nepal's Agricultural Climate Change Adaptation Regime. Systemic Practice and Action Research 28, 4, 383-409.

[7] van Waarden, F. 2012. The Governance Of Markets. On Generating Trust in Transactions. In The Oxford Handbook of Governance, D. Levi-Faur, Ed. Oxford Univ. Press, Oxford, 355-371.

[8] Schedler, K. and Proeller, I. 2011. New public management. UTB Public Management, Betriebswirtschaft 2132. Haupt, Bern.

[9] Torfing, J., Peters, B. G., Pierre, J., and Sørensen, E. 2012. Metagovernance. The art of governing interactive governance. In Interactive Governance Advancing the Paradigm, J. Torfing, B. G. Peters, J. Pierre and E. Sørensen, Eds. Oxford University Press, 122-144. DOI=10.1093/acprof:oso/9780199596751.003.0008.

[10] Moynihan, D. P., Fernandez, S., Kim, S., LeRoux, K. M., Piotrowski, S. J., Wright, B. E., and Yang, K. 2010. Performance Regimes Amidst Governance Complexity. Journal of Public Administration Research and Theory 21, Supplement 1, i141-i155.

[11] Kooiman, J., Bavinck, M., Chuenpagdee, R., Mahon, R., and Pullin, R. 2008. Interactive Governance and Governability:. An Introduction. Journal of Transdisciplinary Environmental Studies 7, 1, 1-11.

[12] Lynn, L. E., JR. 2010. What endures? Public governance and the cycle of reform. In The new public governance. Emerging perspectives on the theory and practice of public governance, S. P. Osborne, Ed. Routledge, London, New York, 105123. 
[13] Axelrod, R. and Cohen, M. D. 2000. Harnessing complexity. Organizational implications of a scientific frontier. Free Press, New York.

[14] Wagenaar, H. 2016. Governance, Complexity, and Democratic Participation. How Citizens and Public Officials Harness the Complexities of Neighborhood Decline. The American Review of Public Administration 37, 1, 17-50.

[15] Liddle, J. 2018. Public Value Management and New Public Governance. Key Traits, Issues and Developments. In The Palgrave Handbook of Public Administration and Management in Europe, E. Ongaro and S. van Thiel, Eds. Palgrave Macmillan UK, London, 967-990. DOI=10.1057/978-1-13755269-3 49.

[16] Torfing, J., Peters, B. G., Pierre, J., and Sørensen, E. 2012. Transparency and governance. In Interactive Governance Advancing the Paradigm, J. Torfing, B. G. Peters, J. Pierre and E. Sørensen, Eds. Oxford University Press, 208-228. DOI=10.1093/acprof:oso/9780199596751.003.0012.

[17] Christensen, T. and Lægreid, P. 2012. Governance And Administrative Reforms. In The Oxford Handbook of Governance, D. Levi-Faur, Ed. Oxford Univ. Press, Oxford, 255-267.

[18] Innes, J. E. and Booher, D. E. 2004. Collaborative policymaking. Governance through dialogue. In Deliberative policy analysis. Understanding governance in the network society, M. A. Hajer and $\mathrm{H}$. Wagenaar, Eds. Theories of institutional design. Cambridge Univ. Press, Cambridge, 33-59.

[19] Ansell, C. 2012. Collaborative Governance. In The Oxford Handbook of Governance, D. Levi-Faur, Ed. Oxford Univ. Press, Oxford, 498-511.

[20] Agranoff, R. 2006. Inside Collaborative Networks. Ten Lessons for Public Managers. Public Administration Review 66, s1, 56-65.

[21] Elsner, W. 2004. The "new" economy. Complexity, coordination and a hybrid governance approach. International Journal of Social Economics 31, 11/12, 1029-1049.

[22] Klijn, E.-H. and Koppenjan, J. 2014. Complexity in Governance Network Theory. Complexity, Governance \& Networks 1, 1, 61-70.

[23] Schiffer, E. 2007. The power mapping tool. A method for the empirical research of power relations. IFPRI Discussion Paper 703. International Food Policy Research Institute (IFPRI), Washington D.C.

[24] Hoffmann-Lange, U. 1989. Positional power and political influence in the Federal Republic of Germany. European Journal of Political Research 17, 1, 51-76.

[25] Homburg, V. 2018. ICT, E-Government and EGovernance. Bits \& Bytes for Public Administration. In The Palgrave Handbook of Public Administration and Management in Europe, E. Ongaro and S. van Thiel, Eds. Palgrave Macmillan UK, London, 347362.

[26] Netchaeva, I. 2016. E-Government and EDemocracy. Gazette (Leiden, Netherlands) 64, 5, 467-477.
[27] Swan, M. 2015. Blockchain. Blueprint for a new economy. Safari Tech Books Online. O'Reilly, Beijing.

[28] Finck, M. 2019. Blockchain Regulation and Governance in Europe. Cambridge University Press, Cambridge.

[29] Seebacher, S. and Schüritz, R. 2017. Blockchain Technology as an Enabler of Service Systems. A Structured Literature Review. In Exploring Services Science. Proceedings. Lecture Notes in Business Information Processing, 12-23.

[30] Brinkmann, M. and Heine, M. 2019. Can Blockchain Leverage for New Public Governance? A Conceptual Analysis on Process Level. In Proceedings of the 12 th International Conference on Theory and Practice of Electronic Governance - ICEGOV2019. ACM Press, New York, New York, USA, 338-341. DOI $=10.1145 / 3326365.3326409$.

[31] Rikken, O., Janssen, M., Kwee, Z., Bolívar, R., and Scholl, H. J. 2019. Governance challenges of blockchain and decentralized autonomous organizations. Information Polity 24, 4, 397-417.

[32] Pignatelli, F., Allessie, D., Sobolewski, M., and Vaccari, L. 2019. Blockchain for digital government. An assessment of pioneering implementations in public services. Publications Office of the European Union, Luxembourg.

[33] Shermin, V. 2017. Disrupting governance with blockchains and smart contracts. Strategic Change 26, 5, 499-509.

[34] Davidson, S., Filippi, P. de, and Potts, J. 2016. Economics of Blockchain. SSRN Journal.

[35] Filippi, P. de and Mcmullen, G. 2018. Governance of blockchain systems. Governance of and by Distributed Infrastructure. Blockchain Research Institute and COALA.

[36] Meijer, D. and Ubacht, J. 2018. The governance of blockchain systems from an institutional perspective, a matter of trust or control? In Proceedings of the 19th Annual International Conference on Digital Government Research Governance in the Data Age dgo '18. ACM Press, New York, New York, USA, 1-9. DOI=10.1145/3209281.3209321.

[37] Rueda, R., Šaljić, E., and Tomić, D. 2020. The Institutional Landscape of Blockchain Governance. A Taxonomy for Incorporation at the Nation State. TEM Journal 9, 1, 181-187.

[38] Kim, H. M., Laskowski, M., and Nan, N. 2018. A First Step in the Co-Evolution of Blockchain and Ontologies. Towards Engineering an Ontology of Governance at the Blockchain Protocol Level.

[39] Golumbia, D. 2015. Bitcoin as Politics. Distributed Right-Wing Extremism. In Moneylab reader. An intervention in digital economy, G. Lovink, N. Tkacz and P. d. Vries, Eds. INC Reader 10. Institute of Network Cultures, Amsterdam, 117-131.

[40] Atzori, M. 2018. Blockchain Governance and The Role of Trust Service Providers. The TrustedChain ${ }^{\circledR}$ Network. The JBBA 1, 1, 1-17. 
[41] Atzori, M. 2015. Blockchain Technology and Decentralized Governance. Is the State Still Necessary? SSRN Journal.

[42] Klischewski, R. 2018. Blockchains zwischen Anarchie und Governance. Steuerungsansätze für die öffentliche Verwaltung. In Multikonferenz Wirtschaftsinformatik 2018. Data driven X - Turning Data into Value : Leuphana Universität Lüneburg, 6.-9. März 2018, P. Drews, B. Funk, P. Niemeyer and L. Xie, Eds. Leuphana Universität Lüneburg Institut für Wirtschaftsinformatik, Lüneburg, 609620.

[43] Rozas, D., Tenorio-Fornés, A., Díaz-Molina, S., and Hassan, S. 2018. When Ostrom Meets Blockchain. Exploring the Potentials of Blockchain for Commons Governance. SSRN Journal.

[44] Reijers, W., O'Brolcháin, F., and Haynes, P. 2016. Governance in Blockchain Technologies \& Social Contract Theories. Ledger 1, 134-151.

[45] Servou, E. 2016. Visualizing power in decisionmaking. A preliminary methodological proposal about mobility policy-making. Master's course in Urban Planning and Management, Aalborg University.

[46] Mayers, J. and Vermeulen, S. 2005. Stakeholder influence mapping. Power tool series, London.

[47] Bryson, J. M., Patton, M. Q., and Bowman, R. A. 2011. Working with evaluation stakeholders. A rationale, step-wise approach and toolkit. Evaluation and program planning 34, 1, 1-12.

[48] Torfing, J., Peters, B. G., Pierre, J., and Sørensen, E., Eds. 2012. Interactive Governance Advancing the Paradigm. Oxford University Press.

[49] Eden, C. and Ackermann, F. 1998. Making strategy. The journey of strategic management. SAGE, London, Thousand Oaks.

[50] Torfing, J., Peters, B. G., Pierre, J., and Sørensen, E. 2012. New roles and role dilemmas in interactive governance. In Interactive Governance Advancing the Paradigm, J. Torfing, B. G. Peters, J. Pierre and E. Sørensen, Eds. Oxford University Press, 145-165. 